
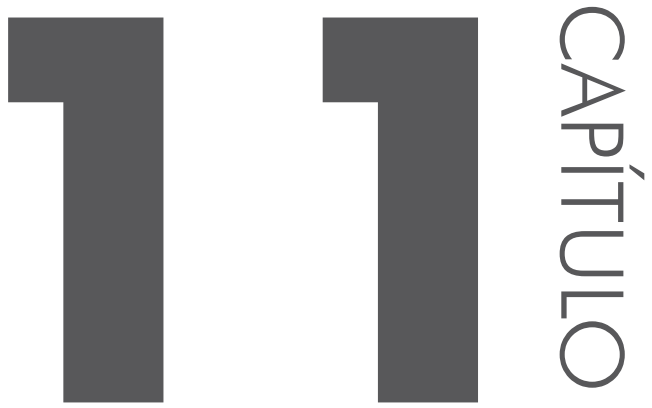

\title{
O PODER E A SOLIDARIEDADE EM CARTAS FEMININAS DO SERIDÓ POTIGUAR
}

Gisonaldo Arcanjo de Sousa

\section{INTRODUC̣ÃO}

Trabalhar a escrita feminina em cartas do Seridó Potiguar é, antes de tudo, contribuir para os avanços dos estudos voltados para as mulheres brasileiras. No Rio Grande do Norte, talvez somente o Seridó nomeie com clareza uma identificação regional, cartográfica, cultural e espacialmente. Tanto isso é verdade que pessoas se denominam "seridoenses”, mesmo por- 
que é dessa maneira que os outros os identificam. Assim, nenhuma outra região potiguar possui um nome próprio que adjetiva, explicitamente, seus habitantes no mercado simbólico do regionalismo norte-rio-grandense. Tal característica não se dá no vazio. É uma tessitura histórica, identitária.

Dessa forma, pode-se dizer que é uma pesquisa que vem contribuir para a dinâmica dos estudos sociolinguísticos voltados especificamente, neste caso, para missivistas femininas em um cenário historicamente masculino como é característica do Nordeste em seus aspectos históricos e sociais.

Trazer à tona as relações de poder e solidariedade, como propostas por Brown e Gilman (2003[1960]), nesse ambiente é revelar, mesmo que timidamente, a voz feminina que subjaz às forças patriarcais do local onde ainda imperam característica única potiguar que passa por momentos dos fundadores da ocupação colonial, pela pecuária, pela economia algodoeira, por dispositivos educacionais, pela religiosidade e pela elite política que, por muito tempo, capitaneou os destinos do Estado do Rio Grande do Norte. Por assim se apresentar, seus resquícios epistolares revelam a alternância do fenômeno da variação e mudança.

A variação observada entre as formas pronominais do $t u$, vocêe $e$ senhor(a) no português brasileiro é uma questão amplamente discutida. De forma tímida, no fim do século XIX, percebe-se a coexistência do tu e do você em referência a um mesmo interlocutor (BARCIA, 2004). Duarte (1993), observando amostras de peças teatrais do Rio de Janeiro, produzidas nos séculos XIX e XX, verifica que o emprego de você supera o uso de $t u$. No entanto, Paredes e Silva (2000) afirma que o $t u$ regressou ao dialeto carioca, sem a flexão da forma verbal adequada de segunda pessoa.

$\mathrm{O}$ interesse pela questão do tuteamento, do voceamento e do senhoramento tem suscitado estudos acerca dos fatores linguísticos que teriam provocado o processo de mudança, por exemplo, de Vossa Mercê > você. $\mathrm{O}$ você se encontra integrado ao sistema de pronomes pessoais, às vezes, substituindo o tu ou convivendo ao lado deste. Também o senhor(a), pronome de tratamento por natureza, vem se distanciando de sua função primeira e está ganhando outra dimensão. Às vezes se o flagra concorrendo com o tu e o você em contextos nada formais.

É interessante investigar as causas das mudanças ocorridas no sistema pronominal do Brasil, especificamente na região do Seridó, observando os fatores linguísticos e também extralinguísticos que motivaram o processo de pronominalização e competição entre as formas tanto por missivistas masculinos, como também femininos.

As vozes masculinas, pelo viés histórico, sempre sobrepuseram as fe- 
mininas. A busca pela voz e vez da mulher com relação ao posicionamento na sociedade é de longa data. Aqui se propõe averiguar como se dá a relação entre mulher e homem em um contexto nordestino-potiguar. A multiplicidade de formas atinge a língua portuguesa no que tange à codificação linguística dos pronomes pessoais usados pelas mulheres seridoenses, precisamente, o TU/VOCÊ/SENHOR(A) (doravante, TVS) dispostos em cartas pessoais escritas na década de 80 do século passado, como exemplificado a seguir:

Caicó - $16-1280$

Cara amiga: Boa tarde

Olá M como está as coisas / aí, tudo bem. VOCÊ está gostando dair, I

Olha quanto aqui não temos novida-/dês. Os meninos não vierão dia 08 (oito) com F. pois C foi para casa em / Fortaleza ti encontar e R também foi para casa em Campos Sales. Quanto a turma da / qui está igual (...)

Caicó, $16-01-81$

Inesquecível amiga:

Beijos:

Recebemos sua carta dia 13, chegou no dia 12.(...) Olha quanto a $\mathrm{H}$, continua louco como sempre, ontem / eu falei com ele por telefone e ele / me pediu pra mim telefonar pra ele / hoje novamente eu dei o recado a ele / e ele riu bastante e disse que TU é muito mais louca que ele (...)

Caicó 17-6-82

querido pai pesso que mi aben / COI. Pai pai recebeu a sua carta /fiquei muito satisfita / eu fiquei boa e o SENHOR ainda ta com problema de dinhero. estou meia apertada aqui

A semântica do poder e da solidariedade, proposta por Brown e Gilman (2003[1960]), discute a inter-relação existente entre o fator linguístico e o social. A teoria aponta que o fenômeno se dá quando é observado o grau de tratamento usado pelos interlocutores em uma dada relação. A escolha de uma das formas tratamentais pelo utente da língua possibilita observar se ele transparece simetria ou assimetria. Os autores utilizam-se do francês para referendar a oposição existente entre TU e VOUS. Para 
$T U$ - forma de intimidade, solidariedade e para VOUS forma de distanciamento, cordialidade, polidez, poder. Grosso modo, o poder é observado pelo uso assimétrico do tratamento e a Solidariedade é verificada pela reciprocidade das formas em uso.

Assim, a semântica do poder se traduz no uso assimétrico e não recíproco do VOUS. O falante que possui status superior usa $T U$ e recebe VOUS em relações sociais. A Semântica da solidariedade é indicada pela simetria das formas no uso. Isso vale tanto para as formas igualitárias, $T U$ $\longrightarrow->$ TU e VOUS $<->$ VOUS.

Estudos mais recentes mostram que a semântica do poder e da solidariedade pe reinterpretada, devido a mudanças e transformações pelas quais passa a sociedade. Wardhaugh (1997), por exemplo, destaca uma nova tendência evolutiva do pronome TU/VOUS ao se deslocar do assimétrico para o simétrico polido VOUS/VOUS e para o simétrico neutro TU/TU.

Desse modo, esta análise busca averiguar o uso do $\operatorname{SENHOR}(a)$, VOCÊ E TU, com base em duas perguntas: i) Qual a frequência de uso das formas em competição (SENHOR(a), VOCÊ e TU em cartas femininas do Seridó, na década de 1980, na posição de sujeito? (ii) Quais as relações de poder e de solidariedade (BROWN; GILMAN, 2003[1960]) emanam das relações entre os remetentes e destinatários das cartas femininas elencadas?

\subsection{METODOLOGIA}

Para emergirem os dados verificou-se a recorrência dos pronomes TVS nas cartas da amostra que, em seguida, foram quantificados. A amostra analisada é constituída por um tipo de carta: as de cunho pessoal. Vale-se esclarecer que se consideram cartas pessoais

correspondências entre pessoas próximas que mantém entre si um relacionamento estreito - parentes próximos, amigos íntimos. Trata-se de uma forma de comunicação eminentemente pessoal, distinguindo-se das cartas comerciais, das cartas de propaganda, de correspondência dirigida a seções de jornais ou revistas, etc. (PAREDES SILVA, 1988, p.24) 
A carta pessoal foi escolhida como material de análise por conter em seu conteúdo temática espontânea. Essa característica íntima pode ser produtiva no que se diz respeito à identificação de fenômenos linguísticos em processo de mudança.

A correspondência epistolar pode, de fato, conter em sua essência tais fenômenos de forma abundante. No entanto, pode ainda, devido a sua estrutura, manter-se fixa, caracterizando-a como gênero discursivo.

Para esta pesquisa, delimita-se um corpus composto por uma amostra de vinte cartas escritas na década de 80 do século passado. As missivas foram enviadas por mulheres seridoenses. As cartas fazem parte dos Corpora Essas Mal Traçadas Linhas I... (SILVA, 2007), composta por cartas de homens e mulheres, e Essas Mal Traçadas Linhas II... (SOUSA, 2014, compostas por cartas femininas.

O gênero carta apresenta em sua estrutura textual os seguintes constituintes: i) o contato inicial - às vezes com a presença da saudação e a captação da benevolência; ii) o núcleo da carta - motivo pelo qual ela foi escrita; iii) a despedida e, por último; iv) a assinatura. Essa estrutura fixa, prototípica, apresenta algumas variações em sua estrutura que pode interferir, além da normalidade, na análise do fenômeno linguístico buscado quando se escolhe esse gênero como material de pesquisa da mudança/ variação.

O quadro 1 resume e estratifica o perfil dos remetentes e destinatários, situa a amostra no tempo, identificando-a em relação à natureza do seu assunto. 
Quadro 1: Estratificação social das cartas em análise

\begin{tabular}{|l|c|c|c|c|}
\hline & Sexo do remetente & Sexo do destinatário & Data da carta & Natureza do assunto \\
\hline Carta 01 & feminino & feminino & $29 / 02 / 1980$ & trabalho \\
\hline Carta 02 & feminino & feminino & $24 / 07 / 1980$ & trabalho \\
\hline Carta 03 & feminino & masculino & $15 / 12 / 1980$ & cobrança de dinheiro \\
\hline Carta 04 & feminino & feminino & $10 / 12 / 1980$ & notícias do dia a dia \\
\hline Carta 05 & feminino & feminino & $17 / 12 / 1980$ & notícias do dia a dia \\
\hline Carta 06 & feminino & masculino & $23 / 12 / 1980$ & notícias do dia a dia \\
\hline Carta 07 & feminino & feminino & $12 / 01 / 1981$ & cobrança de dinheiro \\
\hline Carta 08 & feminino & feminino & $14 / 01 / 1981$ & notícias do dia a dia \\
\hline Carta 09 & feminino & feminino & $16 / 01 / 1981$ & notícias do dia a dia \\
\hline Carta 10 & feminino & feminino & $25 / 01 / 1981$ & aborto \\
\hline Carta 11 & feminino & feminino & $03 / 02 / 1982$ & cobrança \\
\hline Carta 12 & feminino & feminino & $25 / 03 / 1981$ & notícias do dia a dia \\
\hline Carta 13 & feminino & masculino & $18 / 06 / 1981$ & agradecimento \\
\hline Carta 14 & feminino & masculino & $28 / 03 / 1982$ & fim de relacionamento \\
\hline Carta 15 & feminino & masculino & $15 / 08 / 1981$ & notícias do dia a dia \\
\hline Carta 16 & feminino & masculino & $11 / 07 / 1984$ & notícias do dia a dia \\
\hline Carta 17 & feminino & masculino & $22 / 06 / 1984$ & Namoro \\
\hline Carta 18 & feminino & masculino & $28 / 12 / 1983$ & Namoro \\
\hline Carta 19 & feminino & masculino & $20 / 03 / 1984$ & Namoro \\
\hline Carta 20 & feminino & masculino & $22 / 08 / 1984$ & notícias do dia a dia \\
\hline
\end{tabular}

A amostra retirada dos corpora radiografa uma década da escrita feminina no Seridó. Pelo conteúdo dos textos epistolares, observa-se que as missivistas são mulheres, pertencem a uma classe social baixa, umas letradas e outras que não demonstram tanto domínio da escrita. Eles revelam o momento histórico pelo qual passam as escreventes: a seca, o trabalho, a busca pelo emprego, as dívidas financeiras, os amores, as notícias do dia a dia, amizade, entre outros.

Os sujeitos, objetos de estudo, são todas seridoenses, conforme buscas comprobatórias em cartórios da região. Através de entrevistas, constatou- 
-se que a maioria delas não saiu de sua região por mais de dois anos.

Quanto aos destinatários, esses são pessoas da própria família: pai, mãe, irmão, irmã, namorado, esposo, ex-namorado, compadres e comadres.

\subsection{OS RESULTADOS}

Os resultados quantitativos das formas pronominais de tratamento levantadas no corpus da análise de vinte cartas, escolhidas aleatoriamente dos corpora já mencionados, referem-se ao uso do TU, VOCÊ e SENHOR.

Tabela 1: Frequência geral das formas TVS em cartas femininas

\begin{tabular}{c|c|c}
\hline TU & VOCÊ(S) & SENHOR(A) \\
\hline $01 /(0,65 \%)$ & $152(97,43 \%)$ & $03(1,92 \%)$ \\
\hline
\end{tabular}

A predominância do você sobre $t u$ já era de certa forma esperada, tendo em vista que o Seridó experimenta, na dinamicidade da língua, assim como todas as regiões e sub-regiões do país, as pressões advindas do mundo sociocomunicativo. De modo geral, o VOCÊ é o campeão de uso, ficando a curiosidade por conta do aceno para a predominância do tratamento SENHOR sobre O TU, a despeito de se registrar em cartas pessoais. Vale ressaltar aqui que a amostra é escassa para generalizações, porém delineia-se uma preferência pelo SENHOR em lugar do TU.

(4)

Caicó, 16 de julho de 80

A, meu abraço

A finalidade desta linha é para dar / tes ás minhas notícias que estamos todos com saúde / graças a Deus, ás mesmo desejo que / vá tí encontra com os seus. Camp: recebir o dois mil / Cr\$ que o senhor mim enviou muito obrigado Deus lhe der muita saúde e o mente / os seus dias de registência...

A carta (4) é remetida por uma mulher ao seu patrão. No seu conteúdo se vê estampada a relação entre patrão/empregada, sobretudo, captada pelas relações capitalistas mantidas entre os envolvidos. Percebem-se implicitamente os sentimentos de fé e de religiosidade entre as relações seladas pelo respeito ao patrão e a Deus.

O tratamento SENHOR é utilizado formalmente (pelo menos é o que preconiza a gramática tradicional). Assim, cartas pessoais pela sua natureza menos formal não deveriam aparecer com certa evidência competindo com o TU. Talvez a escolha fora condicionada pela dimensão de poder. 
Tabela 2: Frequência das formas TVS na função de sujeito

\begin{tabular}{c|c|c}
\hline TU & VOCÊ(S) & SENHOR(A) \\
\hline $01(0,89 \%)$ & $110(98,22 \%)$ & $01(0,89 \%)$ \\
\hline
\end{tabular}

Predominam nas cartas o uso do você em detrimento do TU e SENHOR. A esse respeito, pode-se guiar pela posição de Brown \& Gilman (2003[1960]), quando consideram que se uma pessoa interage com outra, está exercendo uma sobre a outra, níveis de poder, o que pode acarretar uma assimetria no tratamento. Dessa forma, o tipo de correspondência, assim como a relação emissor - destinatário poderá influenciar na escolha de uma ou de outra forma de tratamento. Observe-se a frequência de uso das TVS, considerando emissores e destinatários específicos, na tabela 3.

Tabela 3: TVS e os receptores das cartas femininas

\begin{tabular}{c|c|c|c}
\hline & TU & VOĈे(S) & SENHOR(A) \\
\hline Mulher para mulher & $01(100 \%)$ & $64(58,19 \%)$ & $00(0,0 \%)$ \\
Mulher para homem & $00(0,0 \%)$ & $46(41,81 \%)$ & $01(100 \%)$ \\
TOTAL & $01(100 \%)$ & $110(100 \%)$ & $01(100 \%)$ \\
\hline
\end{tabular}

Os dados das cartas revelam diferenças entre as cartas escritas de mulheres para mulheres daquelas escritas de mulheres para homens. Os números evidenciam, neste recorte de tempo, (ainda) a submissão histórica que pode existir entre as relações homem-mulher, no cenário seridoense. A subserviência feminina era algo muito presente em décadas passadas, e na década de 80 ainda se respiravam os ares dessa cultura machista, em especial na região do Seridó, onde imperavam resquícios de uma sociedade coronelista muito arraigada, restando à mulher apenas a posição de submissão.

As relações são consequência de uma organização social, ou de fatores convencionais que se envolvem com as diferenças entre a fala dos homens e fala das mulheres.

Segundo Brown e Gilman (2003[1960]), uma pessoa pode exercer o poder sobre a outra na medida em que é capaz de reger o se comportamento, quer seja pelo gênero, pela força física, quer seja pela situação econômica, posição familiar, etc. Tal relação não se configura como recíproca, uma vez que pode variar de acordo com a área de atuação. O poder, ainda, pode estar relacionado a outros fatores como diferença de idade, profissão, etc. características que, por vezes recorrente, atribuem-se ao valor social, dependendo de cada comunidade linguística. 
(5)

Caicó 18 de Junho de 81

Camp. A meu abraço

Afinalidade desta linha é paral dartes ás minhas noticia quel estamos todos com saúde graças I a Deus, ás mesmo desejo que I vá ti encontra com os seus.l Camp: recibir o dois mil cr\$ I que o senhor mim enviou I muito obrigado Deus lhe, der I muita saúde e o mente os seus I dias de registencia. I

Eu mim o pereu no dia 21 do I mês passado e estou muito bem I graça a Deus, diga a M I que eu estou esperando carta I dela hoje faz 15 dias que eu I botei uma carta para ela e ela I escreva logo papai manda dizer I que no dia 15 de Julho estára I ai sendo que Deus não mande I o contrario envio muita | lembrança para o senhor e coma- I M e os meninos e I M papai envia lembranças I o senhor e com. M e I Mamãe envia recomendação I também, vou termina | recomendações I para quen pergunta por $\mid$ min $\mid$

Assinal

Sua comadre que muito lhe, I estima $\mid \mathrm{M}$

Caicó, 16-01-81

Recebi tua carta dia 13, chegou I no dia 12 mas eu estava em Natal e I quando cheguei no dia 13 tinha 6 cartas I pra mim o que é que você acha. Olha I querida quanto ao $\mathrm{G}$ eu já dei teu I endereço para ele e ele me prometeu que I escreveria esta semana. I

Agora querida, quanto ao endereço I do V está difícil, porque além de eu ter I perdido o contato com ele, desde que você I foi embora nunca mais o vi já fui I no projeto mas não o encontrei. Quanto | ao A, não posso te dizer nada, você l lembra que na outra carta eu mandei I te dizer que ele tinha ido a Recife, I pois do Recife ele foi pra Bahia e I não me mandou nem notícia. I O D foi quem me disse que ele I tinha lelefonado para ele dizendo que I só vinha no início de maio pois I as férias dele só termina no dia 15 I de maio e ele volta pro trabalho mas I não mandou nem notícia pra mim I não sei se quando ele chegar ainda I me quer, sei que eu estou esperando I pois estou gamadona e ele me prome- I teu muitas coisas bonitas só não I sei se vai cumprir o que é que I você acha? Esquece. I

Olha, quanto ao $\mathrm{H}$, conti- nua louco como sempre, ontem I eu falei com ele por telefone e ele I me pediu pra mim telefonar pra ele I hoje novamente ei dei teu recado I a ele e ele riu bastante e disse que I tu é muito mais louca que ele. Nos I estamos muito amigos agora, 
quase todos os dias nós telefonamos um I para o outro e é aquele papo de I 30 a 60 minutos. I

Olha menina a vida aqui está I uma droga desde que você foi I embora nunca mais eu sai de casa I olha minha matriculo começa $2^{\text {a }}$ feira I estou louca que comece as aulas, pois I pelo menos eu saio pro colégio já que I não tenho pra onde ir. I

Sim a novidade maior é I que eu estou pensando em ir I pro Rio de Janeiro no próximo I més o que é que você acha? I

me responda logo. I

desculpe a mal carta é I que eu escrevi aqui no Sindicato I e você já sabe como é. I

um forte abraço da I amiga de sempre. I

O H acaba I de chegar aqui, lindo I como sempre. I

Os textos epistolares (5) e (6) ilustram como o usuário seridoense usa as formas TVS, considerando se o destinatário da carta é do sexo masculino ou feminino. As cartas pessoais registram uma abundância de uso do VOCÊ em situações em que mulheres são remetentes e destinatários, como nas situações em que mulheres são remetentes e homens destinatários. As formas do TU e SENHOR aparecem em proporção muito limitada.

Para melhor contextualização, a carta (5) é enviada de uma remetente do sexo feminino para um destinatário do sexo masculino, e conforme pode-se ver retrata relações de amizade, relata situações do dia a dia. A carta (6) é emitida por uma mulher e destinada a outra mulher. Trata também de assuntos do dia a dia. Mas é digno de nota que a carta a qual registra o uso do TU é enviada de mulher para mulher e a que recebe o tratamento SENHOR é de mulher para homem.

Conforme Rumeu (2013, p. 253), o VOCÊ é mais produtivo na escrita de mulheres para mulheres: "as mulheres parecem ter optado por não se exporem a uma construção sintática tão seriamente rechaçada pela norma gramatical: o emprego do Tu sem concordância verbal”. Nesse raciocínio, compreende-se que as mulheres parecem vir contribuindo para o processo de mudança da língua, haja vista que preferem o VOCÊ como forma tratamental na fala seridoense.

Ainda conforme Rumeu (2013), o uso do VOCÊ no Brasil não apresenta estigma social, haja vista que é produtivo em cartas de pessoas ilustres no século XIX. Sendo assim, há mais uma motivação para que o voceamento seja comum no tratamento entre mulheres.

Por questões culturais não é esperado que a mulher seridoense exerça poder sobre o homem, ainda mais em se tratando de linguagem. Sob essa perspectiva, foram controladas a assimetria e simetria dos remetentes/des- 
tinatários, embasando-se não no uso das formas TVS, mas no conteúdo íntimo revelado pelas cartas. Os resultados apontam uma paridade no tratamento, como podemos ver na tabela 4 .

Tabela 4: Relações de poder e solidariedade nas formas TVS

\begin{tabular}{lc|c|c}
\hline & Simetria & Assimetria & TOTAL \\
\hline Mulher para mulher & $07(70 \%)$ & $03(30 \%)$ & $10(100 \%)$ \\
Mulher para homem & $07(70 \%)$ & $03(30 \%)$ & $10(100 \%)$ \\
\hline
\end{tabular}

Das vinte cartas selecionadas para averiguar o nível das relações de poder e solidariedade de Brown e Gilman (1960), dez foram destinadas a mulheres e dez) foram destinadas a homens. Das dez destinadas às mulheres, sete delas revelaram relações simétricas e três revelaram relações assimétricas, no que diz respeito aos níveis de poder e solidariedade; das dez cartas destinadas a homens, sete delas também foram simétricas e três oram assimétricas. Os dados sinalizam certa paridade nas relações de poder e solidariedade emanadas da mulher para o homem ou de mulher para mulher nas cartas analisadas.

Acrescente-se a isso que o contexto das cartas se desenvolve nos anos 80 do século passado, época em que a sociedade vivenciava grandes mobilizações revolucionárias femininas, estando em debate na agenda da época temas como aborto, divórcio, êxodo rural, movimentos que obrigavam a mulher a se portar como homem, em algumas ocasiões.

A forma SENHOR tem apenas uma ocorrência na função de sujeito o que parece radiografar as relações de respeito existentes entre as velhas famílias patriarcais potiguares.

\section{CONSIDERAC̣õES DE CARÁTER NÃO-FINAL}

A análise apresenta pistas acerca do uso das formas TVS pelas mulheres no Seridó potiguar, muito embora essas pistas sejam um tanto limitadas pela escassez da amostra. A forma VOCÉ é a mais recorrente nas relações entre as informantes, principalmente, naquelas cartas cujos emissores e destinatários são mulheres. A frequência de uso do VOCÊ prepondera sobre o SENHOR e o TU, haja vista que, das 156 ocorrências tratamentais registradas nas cartas, 52(97,43\%) delas são de VOCÊ como interlocução entre missivistas; $03(1,93 \%)$ para o SENHOR e $01(0,65 \%)$ para o TU. Esses números, pois, acenam para o fato de que a forma preferida de tratamento da voz feminina seridoense é o VOCÊ, em detrimento do SENHOR, que só foi utilizado em carta dirigida a um patrão, e o TU, que mesmo sendo utilizado em uma ocorrência, parece que ele vem etiquetado com o 
valor de VOCÊ, porquanto se registra que a concordância entre sujeito e verbo é feita no nível da terceira pessoa.

Tais resultados sinalizam para a tendência da mulher seridoense estar contribuindo para uma mudança em progresso do VOC $\hat{E}$, nos contextos informais, uma vez que o prefere em relação às demais formas tratamentais mais do que os homens. 


\section{REFERÊNCIAS}

BARCIA, L. R. As formas de tratamento em cartas de leitores oitocentistas: peculiaridades do gênero e reflexos da mudança pronominal. Dissertação de mestrado. UFRJ: Rio de Janeiro, 2006.

BROWN, R; GILMAN, A. The pronouns of power and solidarity. In: PAULSTON, C. B.; TUCKER, G.R. (eds.). Sociolinguistics The essencial readings. United Kingdom: Blackwell, 2003[1960]. P. 156-176.

DUARTE, M. E. L. Do pronome nulo ao pronome pleno: a trajetória do sujeito no português do Brasil. In: ROBERTS, I; KATO, M. A. (orgs.) Português brasileiro: uma viagem diacrônica. Campinas: Editora da Unicamp, 1993.

FERNANDEZ, F. M. Princípios de sociolinguística Y sociologia del lenguage. Espanha: Ariel, 1998.

MENON,O.P.S. A história de você. In: GUEDES, M; BERLINCK, R.A; MURAKAWA, C. A.A. (Org.) Teoria e análises linguísticas: novas trilhas. Araraquara: Laboratório editorial FCL/ UNESP; São Paulo: Cultura Acadêmica Editorial, 2006, p. $99-160$

PAREDES SILVA, V. L. Cartas cariocas: a variação do sujeito na escrita informal. Tese de Doutorado em Linguística. Rio de Janeiro: UFRJ. Faculdade de Letras, 1988.

PAREDES SILVA, V. L. O retorno do pronome tu à fala carioca. In RONCARATI, Cláudia; ABRAÇADO, Jussara. Português brasileiro: contato linguístico, heterogeneidade histórica, Rio de Janeiro; FAPERJ, 7letras, 2000.

RUMEU, M. C. B. A variação "tu" e "você" no português brasileiro oitocentista e novecentista: reflexões sobre a categoria social gênero. Alfa. São Paulo, 57(2): 545-576, 2013.

SILVA, C. R. Corpora Essas Mal Traçadas Linhas I... Universidade Federal do Rio Grande do Norte, 2007. [inédito]

SOUSA, G. A. Essas Mal Traçadas Linhas II... Universidade Federal do Rio Grande do Norte, 2014; [inédito]

WARDHAUGH, R. An introducion to sociolinguistics. 3.ed. Oxford: Blackwell, 1997. 
252 